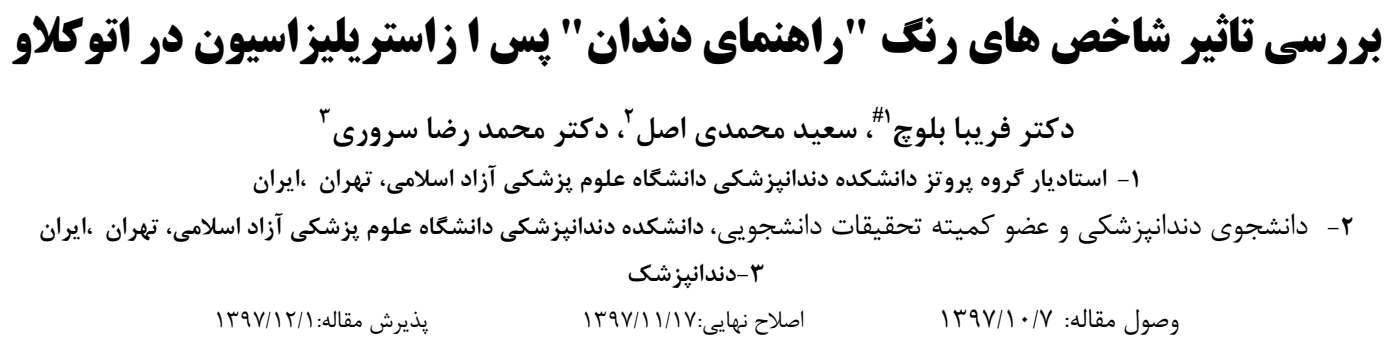

\title{
The effect of autoclave on dental shade guide
}

\author{
Fariba balouch $^{1}$, Saeed mohammadi asl ${ }^{2}$, Mohammadreza Sorori ${ }^{3}$ \\ ${ }^{1}$ Assistant Prof, Prosthodontics Dept, Faculty of Dentistry, Tehran Medical Sciences, Islamic Azad University, Tehran, Iran \\ ${ }^{2}$ Student Research Committee, Faculty of Dentistry, Tehran Medical Sciences, Islamic Azad University, Tehran, Iran \\ ${ }^{3}$ Dentist
}

Received: 28 Decemper 2018; Accepted: 20 February 2019

\section{Abstract}

Background and AIM: The gradual color change of the tooth shade guide is due to the use of an autoclave is one of the clinical problems for correct color reproduction. The purpose of this research was study the effect of autoclave on dental shade guide.

Materials and methods: This experimental experiment was experimental and done on 20 dental paints guide (vitaA3). Subsequently, they were divided into 2 groups color guide by randomly. First, all specimens were washed Before placing in the autoclave Distilled for 3 minutes and they were dry with a tissue and they went on to the autoclave, of course The first group is at $121^{\circ} \mathrm{C}$ for 40 minutes and the second group was kept at $134{ }^{\circ} \mathrm{C}$ for 10 minutes. These specimens were placed in an autoclave with 180 cycles and 3 times a day, 5 days a week (equivalent to 3 months). At each stage set the Spectrophotometer color Indicators (abl) and $\Delta E$ Guide the color of the teeth. Statistical analysis was performed in SPSS software and in the way of Mann-Whitney.

Results: Mean in the group with a temperature of 121 degrees was $3.79 \pm 0.63$ and in the group with a temperature of 134 degrees, it was $3.55 \pm 1.04$ which are not significant. According to the statistical test, there is a difference $(\mathrm{P}<0.3)$. About $\mathrm{b}$ and $\mathrm{c}$ index, difference were minor and no significant difference was observed in the case of other measured indicators, $\mathrm{L}, \mathrm{a}, \mathrm{H}$ in the two groups. $(\mathrm{P}<0.2)$. The color change was more than 3.3 for both method and not acceptable related to clinical subjects. (3.55 and 3.79)

Conclusion: In this study, it was observed that sterilization process by autoclave, can lead to change the color properties of the classic VITA color guide.

Keywords: autoclave, color change, spectrophotometry

*Corresponding Author: drfbalouch@yahoo.com

J Res Dent Sci.2019; 16 (1) :13-19 
سابقه و هدف: تغيير رنغ تدريجى راهنماى رنغَ دندان در اثر استريليزاسيون توسط اتوكلاو يكى از مشكلات كلينيكى جهت

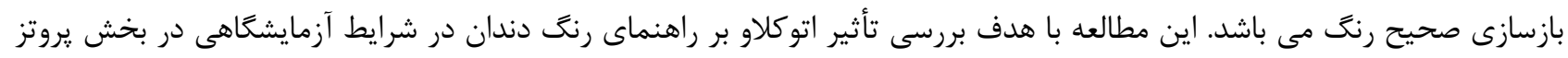

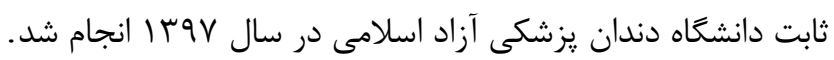

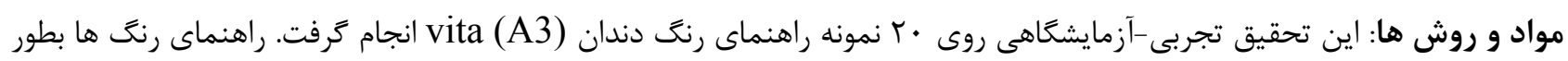

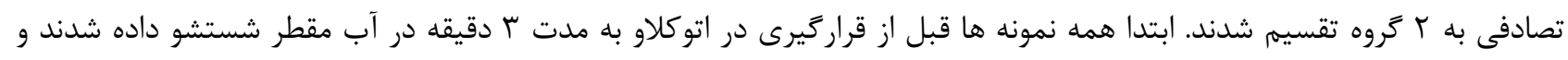

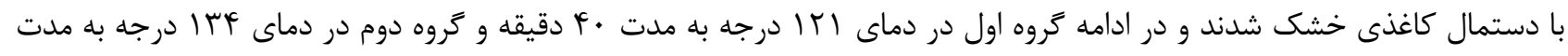

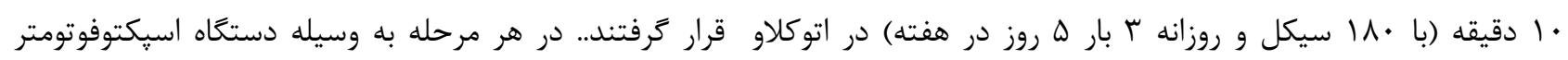

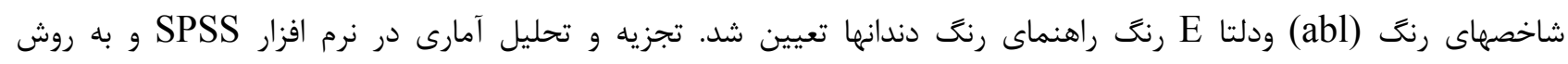
MANN U WHITNEY

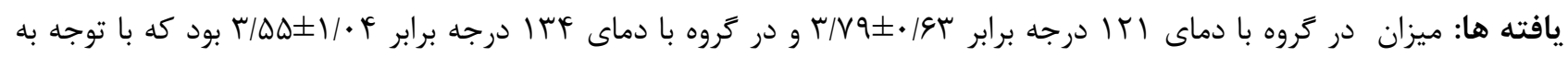

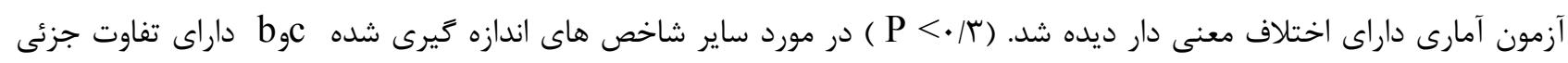

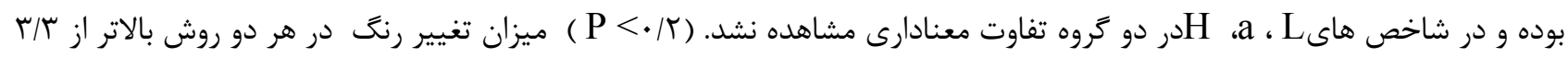

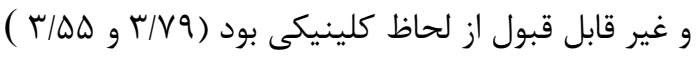

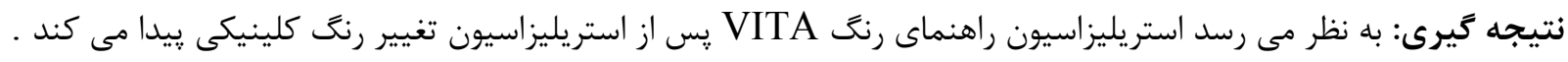

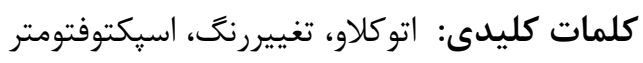

تشكيل شده است كه هـدف آن يوشـش دامنــه رنــ هـا در مقدمه:

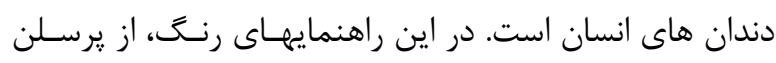

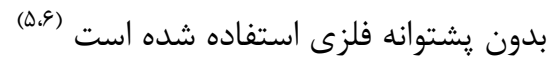
تغيير رنخ راهنماى رنخ دندان يكى از مشكلات بـزرگ بــين تكنسين ها و دندان يزشك ها مى باشد. راهنماى رنت دنى دندان

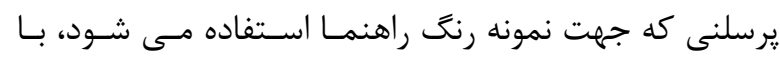
يرسلنى كه براى ساخت رستوريشن به كار مسى رود، متفـاوت

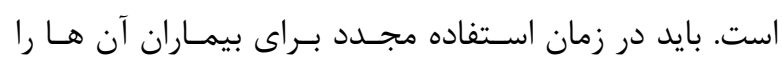
ضدعفونى كرد. اما اين امر مى تواند سبب تغييـرات رنغـى در

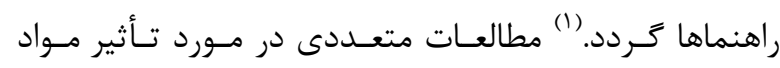

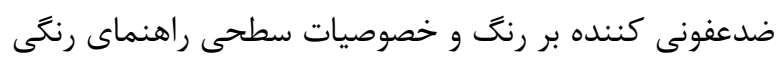

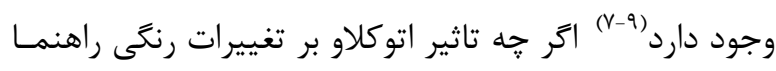
ها كمتر مورد ارزيابى قرار كرفته است .

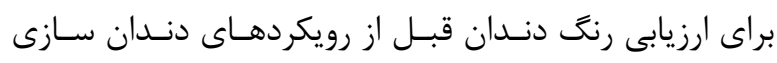

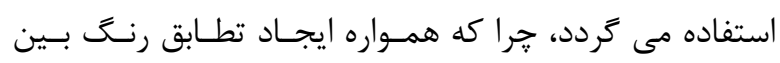

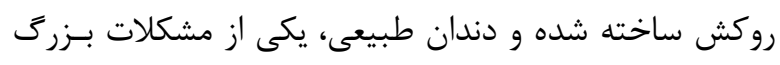

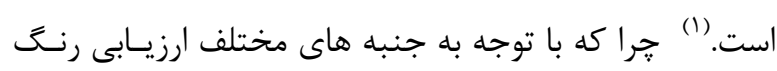

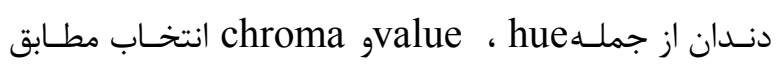

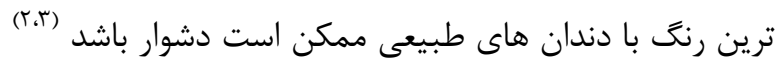

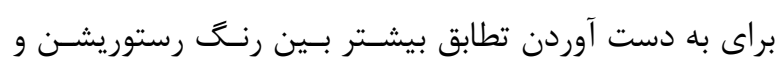

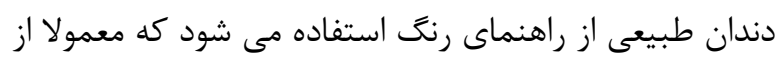

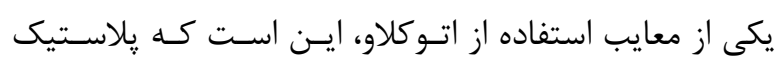

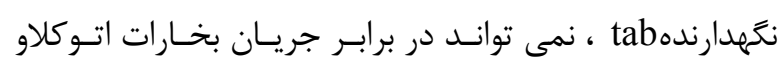

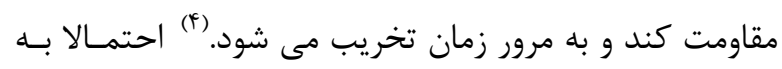

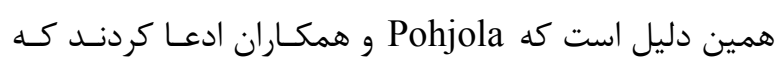
تغييرات رنكى كـه در زمـان استريليزاسـيون توسـط اتـوكلاو

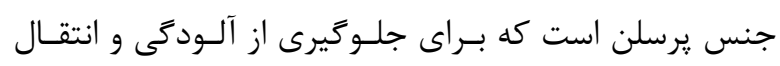

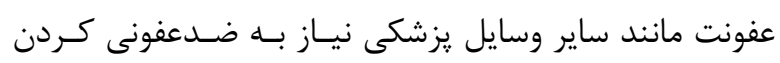

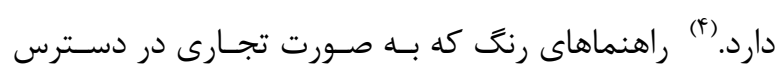

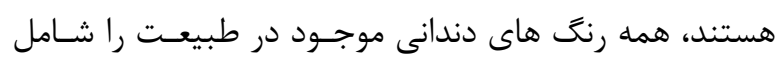

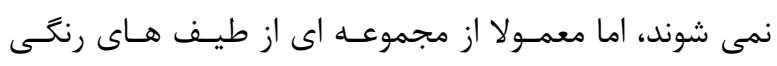


دستخاه اسيكتوفوتومتر (minolta CS2000, Japan) ارزيابى شد. رنگ نمونه ها بعد از اتوكلاو شدن به روش مذكور

نيز توسط دستكاه اسيكتروفتومتر اندازه كيرى شد. (1) اندازه گيرى شاخص هاى رنگ نمونه ها در نور d65 و در

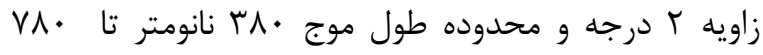

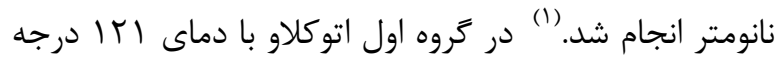
و به مدت • F دقيقه و در كروه دوم با دماى FF أ درجه و به مدت • ا دقيقه انجام ترفت. اين نمونه ها با • 11 سيكل و B روزانه ب بار و ه روز در هفته در اتوكلاو كلاس

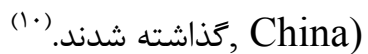
يس از تكميل مراحل اتوكلاو، مجددا راهنماى رنگ دندان به وسيله اسيكتروفتومتر شاخص هاى رنغ (1,a,b) و آن ها

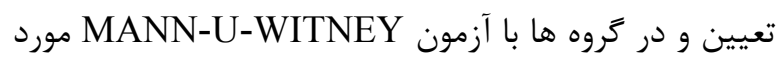

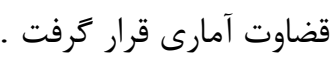

شاخص هاى رنكى به قرار ذيل بود (1) L:روشنى مقابل تيرگى كه رنج بين ( • تا • (د) تيركى و رنج بين (اله تا . ․) روشنى را نشان مى دهد. a قرمز در مقابل سبز كه عدد مثبت قرمز و عدد منفى سبز را رانشان مى دهد. b:زرد در مقابل آبى كه عدد مثبت زرد و عدد منفى آبى را نشان مى دهد.

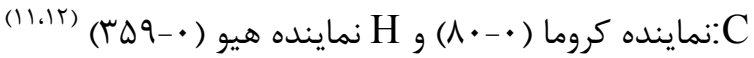
نشان دهنده ميزان تغيير رنخ در زمان هاى مختلف است.

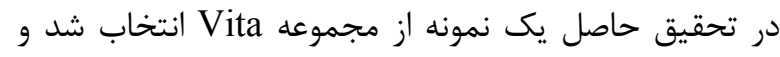
مقادير رنكى آن قبل و بعد از اتوكلاو توسط دستخاه اسيكتروفتر (minolta CS2000, Japan) در محدوده طول

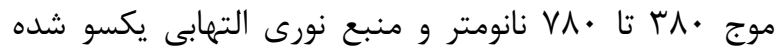
تعيين كرديد. نمونه منتخب در r شرايط مختلف از دما و زمان به شرح گفته شده مورد آزمايش قرار ترفت. دستگاه فوق قادر است بصورت غيرتماسى و تا فاصله حدودا • r مترى پس از كاليبره شدن مقادير بازتابش (انعكاس) نمونههاى مختلف از جمله دندان را تعيين نمايد. نتايج دستخاه بسيار تكراريذير و صحيح مىباشند. علاوه بر آن نتايج
اتفاق مى افتد، يكى از بدترين اثراتى اسـت كـه توسـط ايـن

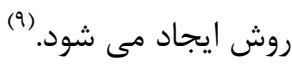
Schemeling همكاران بـهـ منظــور تعيـين تـأثير اتـوكلاو

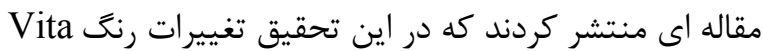
r.classic master

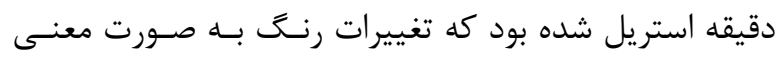
دارى اتفاق افتاده بود. (؟)

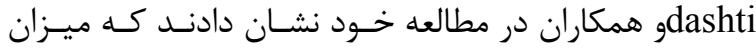
تغيير رنغ راهنماى رنغ دنــان در رونـد ضـدعفونى ممكـن است رنكَ نمونه را تغيير دهد و در نهايت بر رونسد همـاهنكَى رنغ تأثير مى كذارد و بيان كردند كه نمونه هـاى رنغـى كـهـ اتوكلاو شده تغيير رنخَ بسيار بيشترى از نمونه ها ضـدعفونى

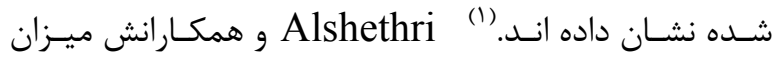
تغيير رنغ راهنماى رنغ دندان در روند ضـدعفونى كـردن را رادها

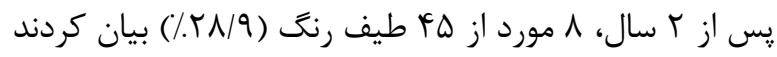
و كَارش نمودند كه ميزان تغييرات رنكى با جشهم انسـان در

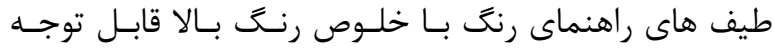

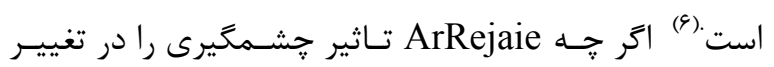
رنغ راهنماى رنغ دندانى در روند ضدعفونى كردن بعـد از ب

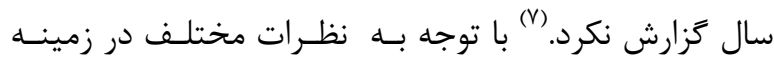

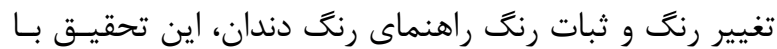

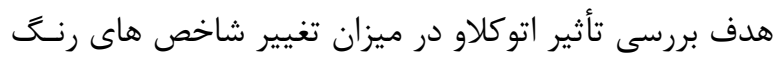
راهنماى رنگ دندان در سال و انجام شد .

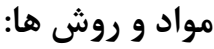

اين تحقيق به روش تجربى و آزمايشگاهى انجام شد. در اين

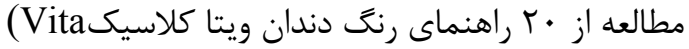
Zahnfabrik, Germany ) دندان ها به طور تصادفى به ץ گروه (در هر كروه • ا نمونه) تقسيم شدند. همه نمونه ها قبل از قراركيرى در اتوكلاو به مدت ץ دقيقه در آب مقطر شستشو داده شدند و با دستمال

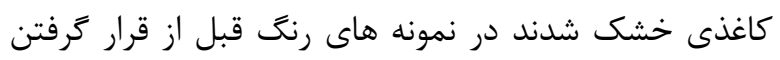

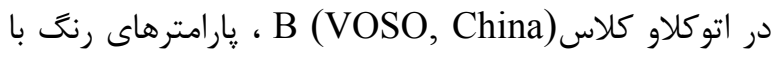


براى نمونه هاى با كلينيكالى قابل قبول نيست بـ بـ

تحقيق بر روى تعداد •ب نمونه و در دو گروه ابا درجه به

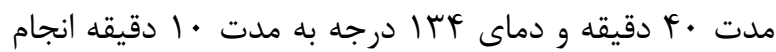
كرفت. (中) مقادير ه شاخص رنغ بر حسب گَروه هاى حرارتى و مدت آن ها در جدول شماره ل ارائه كَرديد و نشان مى دهد

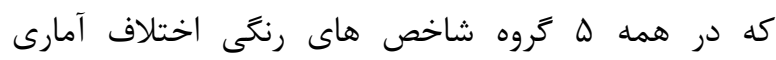
نداشتند. (T/ P (P)
بدست آمده از مختصات رنكَى بين نمونه ها قبل و بعد از اعمال توسط فرمول اختلاف رنغ تحت نام EE *ab تعيين

شد (رابط ا)

$$
\Delta \mathrm{E} \_\mathrm{ab} b^{\wedge *}=\sqrt{ }\left(\left(\Delta \mathrm{L}^{\wedge *}\right)^{\wedge} 2+\left(\Delta \mathrm{a}^{\wedge *}\right)^{\wedge} 2+(\Delta \mathrm{b})^{\wedge} 2\right)
$$

براى تصميم گيرى و قضاوت در خصوص مقدار اختلاف رنگ حاصله قرارداد مندرج در ذيل براى نمونه هاى دندان معرفى

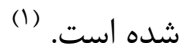

ا-براى نمونه هاى با إ > DE ، نتيجه قضاوت: اختلاف با جشم قابل روئيت نيست. ז-براى نمونه هاى با كلينيكالى قابل قبول است آرخه توسط إيراتور ماهر قابل درك است.

جدول ا- مقادير مختصات رنكى در دو كروه قبل از انجام آزمايش

\begin{tabular}{|c|c|c|c|c|c|}
\hline $\mathbf{L}$ & $\mathbf{a}$ & b & c & H & ات. كاخص رنت \\
\hline $99 / 94 \pm 1 / 99$ & $-\cdot 10 \cdot \pm \cdot / 199$ & $1 \mathrm{~V} / \cdot 9 \pm \cdot / \mathrm{Vq}$ & $\mid \mathrm{V} / \cdot 9 \pm \cdot / \mathrm{Vq}$ & $9 \cdot / 19 \pm 1 / \cdot 1$ & دماى |r| مدت • \\
\hline$\varepsilon 9 / \Delta V \pm 1 / 9 r$ & $-\cdot / / \Lambda \pm \cdot / \Upsilon \vee$ & $19 / V 9 \pm \cdot / \Delta T$ & $|\varepsilon / \vee 9 \pm \cdot| \Delta \mid$ & $q \cdot \mid q 4 \pm 1 / r V$ & دماى F با مدت ·1 \\
\hline $\mathrm{P}<\cdot / 91 \mathrm{r}$ & $\mathrm{P}<\cdot / \pi / \Delta$ & $\mathrm{P}<\cdot / \pi \mid \wedge$ & $\mathrm{P}<\cdot / \pi \mid \wedge$ & $\mathrm{P}<\cdot / r \Delta \mu$ & نتيجه آزمون \\
\hline
\end{tabular}

تغييرات رنغ دندان ها بر حسب شاخص هاى ينج كانه و به تفكيك مدت دماى اتوكلاو و مدت آن در جدول شماره ؟ ارائه

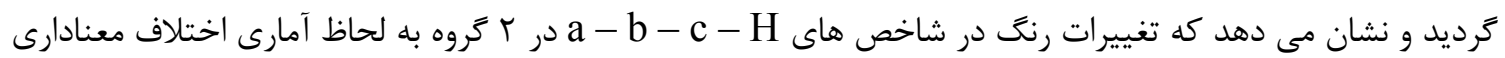

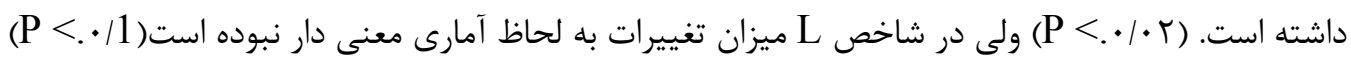
جدول r- تغييرات رنگ راهنماى رنتى دندان بر حسب شرايط استفاده از اتوكلاو

\begin{tabular}{|c|c|c|c|c|c|}
\hline $\mathbf{L}$ & $\mathbf{a}$ & b & c & H & ل \\
\hline$G \psi / \Delta \Delta \pm \cdot / \mathscr{} V$ & $\cdot / r T \pm \cdot / r V$ & $\mid F / T r \pm \cdot / 4 r$ & $\mid f / K r \pm \cdot / f F$ & $19 / 11 \pm \cdot / 1 \Delta$ & دماى |r| مدت ب \\
\hline$q 4 / / f \pm . \mid q$. & $\cdot / 1 \Delta \pm \cdot / V F^{f}$ & $|\psi| q \mid \pm \cdot / r r$ & $\mid F / G Y \pm \cdot / r T$ & $19 / 4 \cdot \pm \cdot / \pi q$ & 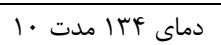 \\
\hline $\mathrm{P}<\cdot / 1$ & $\mathrm{P}<\cdot / \cdot 1 \phi$ & $\mathrm{P}<\cdot / \cdot \mathrm{Fr}^{2}$ & $\mathrm{P}<. \cdot / \cdot r \Delta$ & $\mathrm{P}<\cdot / \cdot . \mathrm{F}$ & نتيجه آزمون \\
\hline
\end{tabular}

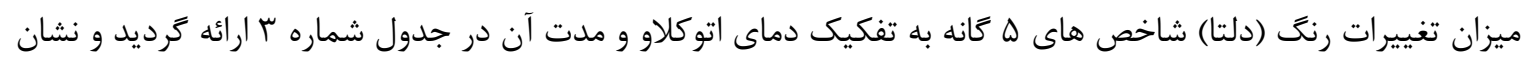

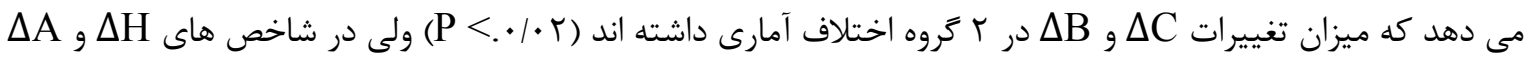

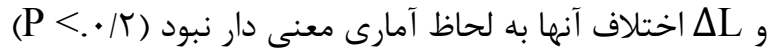




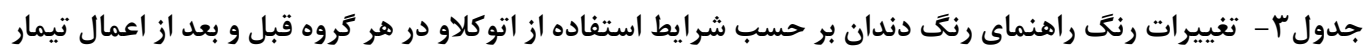

\begin{tabular}{|c|c|c|c|c|c|}
\hline$\Delta \mathbf{L}$ & $\Delta \mathbf{a}$ & $\Delta \mathbf{b}$ & $\Delta \mathbf{C}$ & $\Delta \mathbf{H}$ & تغييرات , \\
\hline$-r / . ৭ 9 \pm I / r r$ & $\cdot / r V \mid \pm \cdot / r q$ & 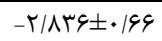 & $-r / \Lambda r \cdot \pm \cdot \mid q \Lambda$ & $-1 / \cdot 1 \cdot \pm 1$ & دماى /T| مدت . \\
\hline$-\Gamma / F r \Lambda \pm I / \Delta \Lambda$ & . & $-r /|\vee q \pm \cdot| q \mid$ & $-\Gamma / / V \cdot \pm \cdot / \varphi$. & $-1 / K 4 \mid \pm 1 / 4 \varphi$ & دماي frا مدت .1 \\
\hline $\mathrm{P}<\cdot / \Delta \vee q$ & $\mathrm{P}<\cdot|94|$ & $\mathrm{P}<\cdot 1 \cdot 19$ & $\mathrm{P}<\cdot / \cdot 10$ & $\mathrm{P}<\cdot / \wedge \Delta \Gamma$ & نتيجه آزمون \\
\hline
\end{tabular}

استفاده شد جرا كه اين يارامترها بيشتر با سيستم انتخاب رنغ vita كلاسيك مطابقت دارند، در واقع L نماينده روشنايى و تاريكى يك شئ (100-0) و C, نماينده كروما

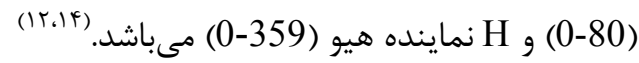

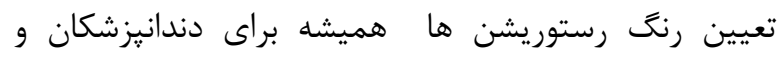
بيماران در انجام فرآيندهاى زيبايى مسئلهاى مهم بوده است و براى بيماران يكى از مهمترين مسائل در قضاوت جذابيت و زيبايى يك فرآيند ترميمى اتمام يافته، رنغ دندان ترميمى مىباشد. (9) تعيين رنغ مىتواند بسيار دشوار و يِيجيده باشد.

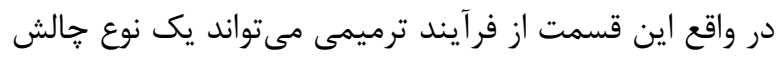
باشد خرا كه ذات خاصيت رنغ و درك آن فرآيندى فردى

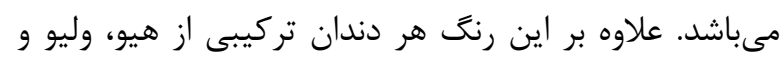
كروما و شفافيت مىباشد كه از لبه انسزيال تا لبه لثهاى

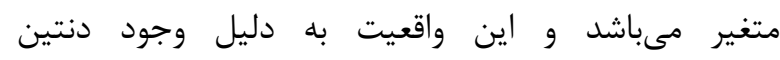

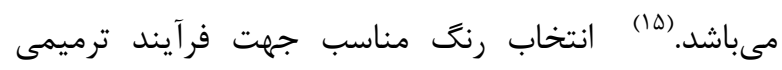
فاكتورهاى بسيارى نقش دارند. براى مثال انتخاب فضا و نور مناسب، سلامت بينايى دندانيزشك، استفاده از راهنماى انتخاب مناسب، تبحر دندانيزشك و ... از اين دست مىباشند، با اين وجود تعيين رنغ مناسب توسط ايراتورهاى مختلف با شرايط يكسان بسيار متفاوت بوده است و حتى يك إيراتور در جند نوبت رنگهاى متفاوت را در شرايط يكسان انتخاب

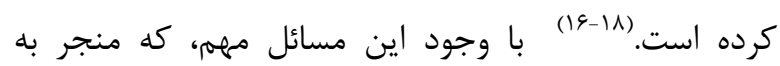

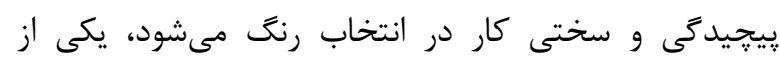

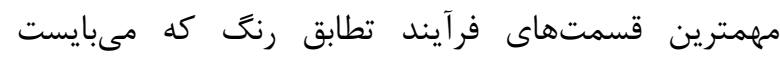
هميشه ثابت و بدون تغيير بماند، راهنماى انتخاب رنت مورد
تغييرات رنگ دندان (DE) بر حسب كروه ها در جدول F

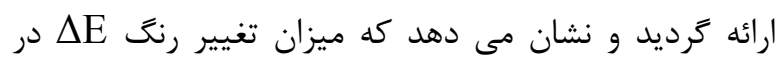

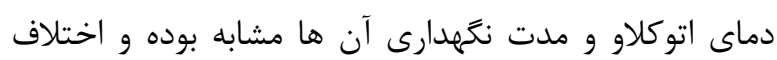

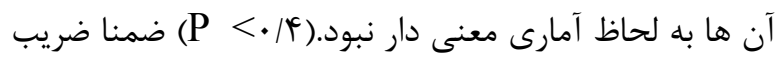
1.

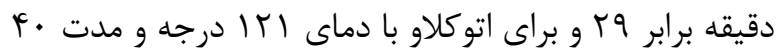
دقيقه برابر 19 بود.

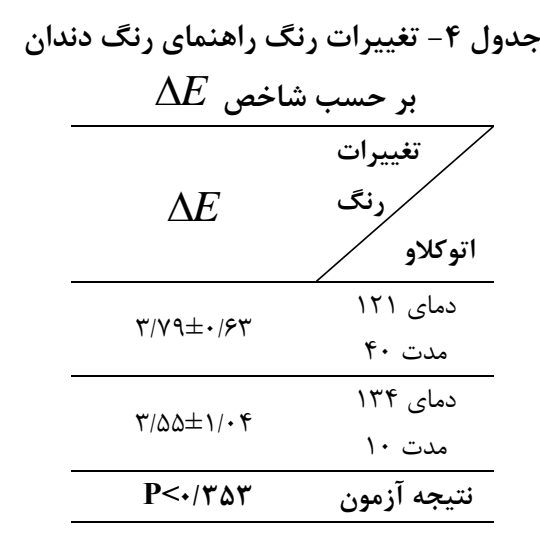

نتايج اين مطالعه حاكى از آن بود كه در شاخص هاى a و b و و C مقادير كزارش شده داراى اختلاف معنى دار در دو

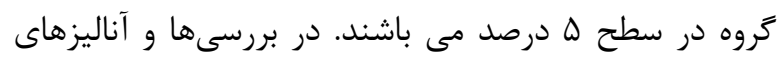

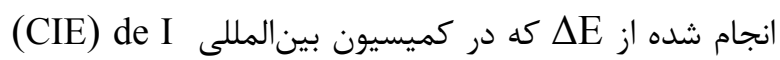
Edairage استفاده شد. در سيستم L, CIE نماينده روشنى، a نماينده

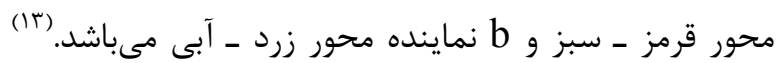

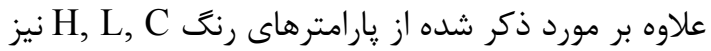


اول، دوم و سوم در گروه اتوكلاو و نسبت به گروه ضدعفونى بيشتر بوده است همجنين تفاوت در كروما به صورت افزايش در ميزان كروما در هر ب سال در گروه اتوكلاو و كاهش در هر r سال در زروه ضدعفونى بوده است، شايد اين تفاوت معنى دار را بتوان اينگونه توجيه كرد كه تكنيكهاى مختلف ساخت كيتهاى انتخاب رنت منجر به نتايج متفاوتى در مورد اثرات مواد ضدعفونى مىشود به طورى كه براى مثال كيتهاى انتخاب رنكىى كه به وسيله لايههاى مختلف يرسلن (مانند آنجه كه در Vita classic shade guide مشاهده مىشود) ساخته مىشود مقاومتر نسبت به تغيير رنغ، در مقابل آن دسته از كيتهاى انتخاب رنغى كه به وسيله افزودن سطوحى از رنت به رزين و رِختن آنها ساخته مىشوند، مىباشند به همين دليل در مطالعه حاضر اتوكلاو، فشار و گرما مىتواند بر روى كل ساختار آن تأثير كذارد. بنابراين توصيه مى شود جهت بررسى اين متغير از كيت هاى

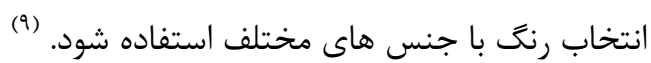

\section{نتيجه گَيرى:}

طبق يافته هاى اين مطالعه مشاهده شد كه فرآيند استريليزاسيون توسط اتوكلاو، مىتواند منجر به تغيير ويزگى هاى رنت كيتهاى انتخاب رنت شود.و اين تغيير رنت از لحاظ بالينى اثر كذار است.

استفاده مىباشد. از طرف ديگر مىدانيم كه راهنماى انتخاب رنگ مىبايست پس از هر نوبت استفاده تحت فرآيندهاى

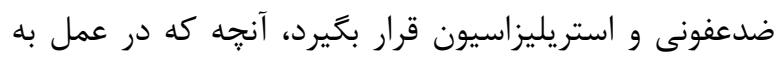
نظر مىآيد و مطالعات اندى صورت كَرفته در اين زمينه نشان مىدهد، اين است كه فرآيندهاى استريليزاسيون و ضدعفونى مىتواند موجب تغيير در رنت نمونه رنغَهاى مختلف شود كه اين امر مسئلهاى مههم در (shade tab) فرآيندهاى ترميمى مىباشد، جرا كه مىتواند قضاوت و

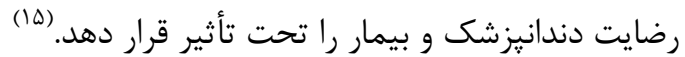
يافتهاى مطالعه با مطالعه Fahmy و همكاران كه به بررسى

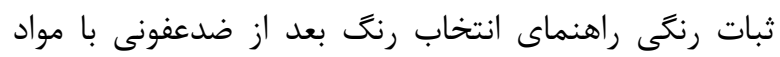

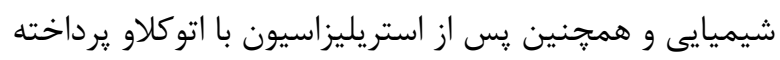

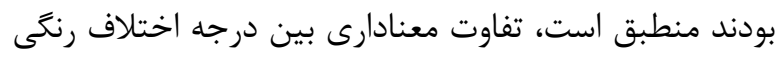

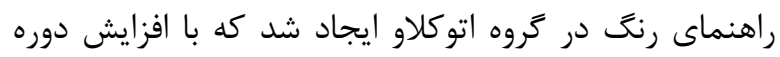
زمانى، اين اختلاف بيشتر نيز شد.(.) اختلاف رنغ ايجاد شده در مطالعه ما با يافته هاى مطالعه مغايرت داشت خرا كه نتايج مطالعه ايشان Schmeling برعكس ما تكرار گرخه هاى اتوكلاو سبب معنى دار شدن اختلاف آمارى نمونه هاى استريل شده در مقايسه با نمونه هاى اوليه شد. البته اين اختلاف آمارى از نظر بالينى قابل قبول بود.(^) در مطالعه Akman و همكاران كه به بررسى تأثير ضدعفونى

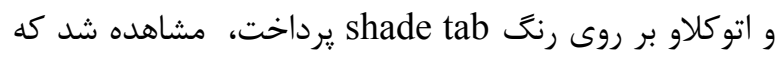
هيج تفاوت معنىدارى در بررسى يك ساله در هينج كدام از روشها وجود نداشته است كه با نتايج بررسى سه ماهه ما

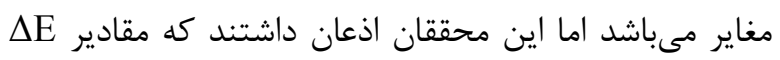

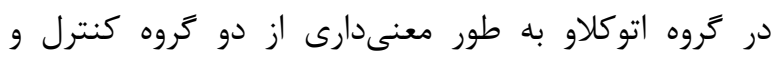

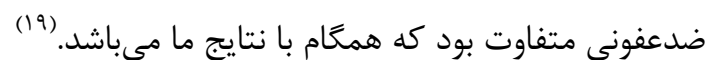
و وممكاران نيز در مورد متغير DE PE نتايج تقريبا مشابهى را با مطالعه حاضر بيان كردند به طورى كه تفاضل

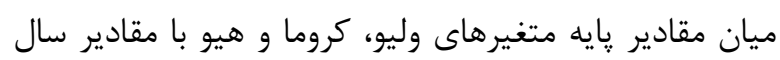

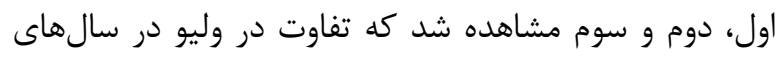




\section{References:}

1.Dashti H, Moraditalab A, Mohammadi M, Rajati Haghi H. Assessment of Color Changes in Vita 3DMaster Shade Guide after Sterilization and Disinfection. Journal of Dental Materials and Techniques 2017;6(2):p. 48-53.

2.Ma T, Johnson GH, Gordon GE. Effects of chemical disinfectants on the surface characteristics and color of denture resins. J Prosthet Dent 1997; 77(2): p. 197-204.

3.Joiner A. Tooth colour: a review of the literature. J Dent 2004; 32 Suppl 1: p. 3-12.

4.Schmeling M, Sartori N, Monteiro S, Baratieri L. Color stability of shade guides after autoclave sterilization. Int $\mathrm{J}$ Periodontics Restorative Dent 2014; 34(5): p. 689-93.

5.O'Brien, W.J., C.L. Groh, and K.M. Boenke, A new, small-color-difference equation for dental shades. J Dent Res 1990; 69(11): p. 1762-4.

6.Alshethri, S.E., Evaluation of color changes in the Vitapan Classical Shade Guide after disinfection. Oper Dent 2014; 39(3): p. 317-24.

7.ArRejaie, A.S. The effect of chemical disinfectants on the color of a porcelain shade guide. International journal of health sciences $2014 ; 8(3)$ : p. 299-304.

8.Huang PY, Masri R, Romberg E, Driscoll CF. The effect of various disinfectants on dental shade guides. J Prosthet Dent 2014. 112(3): p. 613-7.

9.Pohjola, R.M., S.T. Hackman, W.D. Browning Evaluation of a standard shade guide for color change after disinfection. Quintessence Int, 2007. 38(8): p. 671-6.

10.Fahmy M.A, S.A. Maglad. Color Stability of Shade Guides After Disinfection and Autoclave Sterilization. Journal of American Science 2015. 11(12): p. 89-95.

11.Sikri, V. Color: Implications in dentistry. Journal of Conservative Dentistry 2010; 13(4): p. 249-255.

12.Yap A.U, S. Bhole, K.B Tan, Shade match of tooth-colored restorative materials based on a commercial shade guide. Quintessence Int 1995; 26(10): p. 697-702.

13.WESTLAND S. Review of the CIE System of Colorimetry and Its Use in Dentistry. Journal of Esthetic and Restorative Dentistry 2003; 15(s1): p. S5-S12.

14. Analoui M, Papkosta E, Cochran M, Matis B. Designing visually optimal shade guides. The Journal of Prosthetic Dentistry 2004; 92(4): p. 37176.

15.Al Amri M. THE EFFECT OF DISINFECTING SOLUTIONS ON THE COLOR OF PORCELAIN SHADE GUIDES. Vol. 54. 2008. 1057-66.
16. Kuehni, R.G. R.T. Marcus, An Experiment in Visual Scaling of Small Color Differences. Color Research \& Application 1979; 4(2): p. 83-91.

17.Pizzamiglio E. A color selection technique. Journal of Prosthetic Dentistry 1991; 66(5):p.59296.

18.Lagouvardos PE, Fougia AG, Diamantopoulou SA, Polyzois GL.Repeatability and interdevice reliability of two portable color selection devices in matching and measuring tooth color. The Journal of Prosthetic Dentistry 2009; 101(1):40-5.

19.Akman S, Eraslan O, and F. Aykent. Effect of various disinfection procedures on color stability of shade-guides. in PEF IADR Queen Elizabeth II Conference Centre London 2008; 10-12.

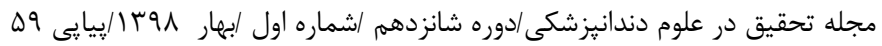

